\title{
Managing acutely aggressive or agitated people in a psychiatric setting: a survey in Lebanon
}

\author{
Joseph E. Dib*1, Clive E. Adams², Francois Kazour ${ }^{3,4,5,6}$, Fouad Tahan ${ }^{3}$, Georges Haddad ${ }^{3,5}$, \\ Chadia Haddad ${ }^{3}$, Souheil Hallit ${ }^{3,7}$
}

\begin{abstract}
Background: Violent patients constitute $10 \%$ of all psychiatric admissions. Treatment options and clinical practice interventions vary across the globe and no survey of practice in a Middle Eastern setting exists. Surveying treatments in Lebanon will show treatment interventions used in this part of the world and, most importantly, provide the treatment options that could potentially be used for clinical trials pertaining to emergency psychiatry.

Methods: A survey of clinicians' opinions and practice was conducted between July and August 2017 at the largest psychiatric hospital in Lebanon.

Results: Five of seven experienced psychiatrists provided opinions when interviewed of their preferred intervention when dealing with an emergency psychiatric episode. Whilst this varied in detail, there was a consistent view that there should first be verbal control, then use of medications, and finally physical restrain of the patient. A total of 39 emergency episodes ( 28 people) occurred in the one month (64\% men in their 30s). Bipolar disorder was the most frequent single diagnosis behind the aggression ( $\mathrm{n}=16,41 \% ; 12$ people $43 \%$ ) but the combined schizophrenia-like illnesses underlay 18 of the 39 episodes (46\%; 13/28 people $46 \%)$. In clinical life, we found evidence of high family involvement, but little attempts made at initial verbal control in the hospital. All 39 episodes involved administration of pharmacological interventions. Medications were used in 29 of cases (74\%) and non-medication interventions used in the remaining 10/39 (26\%).

Conclusion: This survey provides some evidence that clinicians' preferences may not fully reflect clinical practice but also that experienced clinicians are using several clearly effective techniques to manage these very difficult situations. However, as for other parts of the world, treatment in Lebanon has limited or no underpinning by evidence from well-designed, conducted and reported evaluative studies.
\end{abstract}

Keywords: Aggression, Agitation, Survey, Psychiatric hospital, Lebanon, Pharmacotherapy

Copyright $\odot$ Iran University of Medical Sciences

Cite this article as: Dib J, Adams CE, Kazour F, Tahan F, Haddad G, Haddad Ch, Hallit S. Managing acutely aggressive or agitated people in a psychiatric setting: a survey in Lebanon. Med J Islam Repub Iran. 2018 (15 July);32:60. https://doi.org/10.14196/mjiri.32.60

\section{Introduction}

Aggressive and violent behaviour is a common phenomenon seen in the psychiatric setting with an average of $10 \%$ of psychiatric patients prone to a violent episode requiring rapid tranquilization (1). Guidelines recommend aggressive patients to be 'verbally tranquilised' in order

Corresponding author: Joseph Dib, joseph.dib@nottingham.ac.uk

1. Division of Psychiatry and Clinical Psychology, School of Medicine, University of Notting ham, Nottingham, UK.

2. Institute of Mental Health, University of Nottingham, Nottingham, UK.

3. Hôpital Psychiatrique De La Croix, Jal Eddib, Lebanon.

4. Department of Psychology, Holy Spirit University of Kaslik, Kaslik, Lebanon, \& INSERM U930, équipe 4 "Troubles affectifs", Université François-Rabelais de Tours, Parc de Grandmont, 37200 Tours, France.

5. Faculty of Medicine, Saint-Joseph University, Beirut, Lebanon.

6. Faculty of Sciences, Lebanese University, Beirut, Lebanon.

7. Faculty of Pharmacy, Lebanese University, Beirut, Lebanon, \& Faculty of Pharmacy, SaintJoseph University, Beirut, Lebanon, \& Faculty of Medicine and Medical Sciences, Holy Spirit University of Kaslik, Kaslik, Lebanon, \& Occupational Health Environment Research Team, U1219 BPH Bordeaux Population Health Research Center Inserm - Université de Bordeaux Bordeaux, France, \& INSPECT-LB: Institut National de Sante Publique, Epidemiologie Clinique et Toxicologie, Faculty of Public Health, Lebanese University, Beirut, Lebanon. for the attending physician to accurately and safely perform a diagnostic history and physical examination (2). Aggressive patients may make this process difficult and potentially impossible and doctors and nurses face a dilemma and are required to work with limited knowledge.

$\uparrow$ What is "already known” in this topic:

Surveys of opinion and practice looking at emergency management has shown that clinicians' opinions on interventions do not necessarily reflect what really happens in practice.

\section{$\rightarrow$ What this article adds:}

This first Middle Eastern survey of psychiatric emergency room practice illustrates how, like elsewhere, what clinicians wish to happen and what actually occurs in clinical front-line practice is somewhat different. 
Since the psychiatric team has a responsibility of ensuring the safety of everyone, rapid and safe tranquilisation may become an unavoidable option (3).

Medication, restriction within a safe environment and physical restraints are available options to calm an agitated patient. Medication can be given orally (including aerosol or swiftly dispersible tablet), intravenously (IV) or intramuscularly (IM). Often oral and IV medications are impossible when the patient is lashing out aggressively. Restriction or restraints may include the use of a seclusion room or safe space, physical restraints by binding the patient safely to a bed, straitjackets, or holding the person down with or without physical restraints. All options are unpleasant and infringe freedom; all have advantages and disadvantages (4). For example, IV medication may work faster when tranquilising an agitated patient but may also lead to cardiac and respiratory problems - not to mention extreme difficulties of delivering the treatment intravenously into an aggressive patient (5). IM medications are easier to administer making them more efficient in terms of implementation but the time to onset of effect is longer and less predictable than for IV (6). Physical restraints prevent aggressive patients from physically assaulting staff or themselves. Their use may have the advantage allowing safer delivery of IV or IM medication and, perhaps lower and less frequent doses of the latter (7). An additional advantage is that they allow control of difficult behaviour in a situation where staff numbers are not high and provision of high staff attendance to one patient will result in relative neglect of others. The disadvantages, however, are considerable, with the overt restriction of people's freedom. Restraining a person is associated with the danger of death via asphyxiation, trauma or cardiac event (8). All methods are coercive and have potential to be abused. Using the least restrictive option is desirable, but this differs depending on setting, treatment availability, clinicians' preference and skill set, and current custom of practice.

Evidence underpinning the treatments is limited. Randomised trials in this area are difficult and few treatment options are supported by large unbiased trials with clear outcomes of clinical value (Table 1 . Reviews of clinical trials on agitation and interventions) (9-25). Understanda- bly, guidelines differ in their recommendations in line with the limited evidence and local clinical preferences.

As preparatory work for a local randomised trial, a survey of clinicians' treatment preference and practice in Lebanon was undertaken mirroring work done in Brazil (26). The aim of this study was to survey the opinion of attending clinicians on how acute aggression should be managed and to compare it with actual clinical practice. The major reason this survey is titled 'survey of treatment in Lebanon' is mainly due to the fact that the Psychiatric Hospital of the Cross is the largest and only major psychiatric public hospital exists in the country; therefore though limited, it reflects the only available treatment options that could potentially be surveyed.

\section{Methods}

The study excluded children $(<18)$ and the elderly $(>65)$. Eligible participants were selected on the basis of being admitted to the psychiatric hospital and having an agitated episode that required rapid tranquilisation.

\section{Site}

The survey was carried out between July and August 2017 in the Psychiatric Hospital of the Cross (PHC), the largest psychiatric hospital in Lebanon.

\section{Ethical aspect}

These surveys were carried out after gaining ethical approval from the University of Nottingham specifically the Division of Psychiatry and Applied Psychology in the School of Medicine and is overseen by the Faculty of Medicine \& Health Sciences' Research Ethics Committee (Reference number 242). The application was in line with the University of Nottingham's Code of Research Conduct and Research Ethics (2016). The Psychiatric Hospital of the Cross Ethics and Research Committee, in compliance with the Hospital's Regulatory Research Protocol also approved the study design based on the facts that it was an observational study that respected participants' autonomy and confidentiality and induced minimal harm to them. Written consents were obtained from clinicians and patients. Patients with no proper mental status to give consent were under care of the attending physician responsi-

Table 1. Reviews of clinical trials on agitation and interventions

\begin{tabular}{|c|c|}
\hline \multicolumn{2}{|l|}{ Completed and maintained reviews } \\
\hline 'As required' medication regimens for seriously mentally ill people in hospital & (9) \\
\hline Benzodiazepines for psychosis-induced aggression or agitation & $(10)$ \\
\hline Chlorpromazine for psychosis-induced aggression or agitation & (11) \\
\hline Clotiapine for acute psychotic illnesses & $(12)$ \\
\hline Containment strategies for people with serious mental illness & (13) \\
\hline De-escalation techniques for psychosis-induced aggression & (14) \\
\hline Droperidol for acute psychosis & $(15)$ \\
\hline Haloperidol for long-term aggression in psychosis & (16) \\
\hline Haloperidol for psychosis-induced aggression or agitation (rapid tranquillisation) & $(17)$ \\
\hline Haloperidol plus promethazine for psychosis-induced aggression & (18) \\
\hline Olanzapine IM or velotab for acutely disturbed/agitated people with suspected serious mental illnesses & (19) \\
\hline Seclusion and restraint for serious mental illnesses & $(20)$ \\
\hline Zuclopenthixol acetate for acute schizophrenia and similar serious mental illnesses & $(21)$ \\
\hline \multicolumn{2}{|l|}{ Reviews in the process of being completed } \\
\hline Risperidone for psychosis-induced aggression or agitation & $(22)$ \\
\hline Loxapine inhaler for psychosis-induced aggression & $(23)$ \\
\hline Clozapine for people with schizophrenia and recurrent physical aggression & $(24)$ \\
\hline Quetiapine for psychosis-induced aggression or agitation & $(25)$ \\
\hline
\end{tabular}


ble for the patient. Patients were not given any experimental drugs but rather the hospital's routine practice intervention during emergency situations.

\section{Forms}

Clinician's opinion

Form 1 had space to record clinicians' opinions on which intervention techniques should be used when treating an agitated patient. There was no limit on intervention options. The simple form also could be used to gather information on the duration of clinicians' mental health experience as well as current estimates of how often does he or she treats agitated patients (See Form 1 in Appendix).

\section{Clinical practice}

Form 2 was used to record practice for every episode of emergency management within the hospital, within the time period; one form for each agitated episode. This form was also simple and quick to complete. A unique identifier was assigned to every patient, as were details of the ward and whether the patient thought to be new or someone already known to services. A suspected cause for the aggression was noted, along with the suggested diagnosis. Age and sex were included. The form held space for a 'Presentation' variable encouraging recording of how the person arrived - via family, authorities, friends, by themselves or 'others'. The form also had space for recording of whether the patient was restrained or/and received medication before admission. Finally, the form left space to list all treatments administered to the person (See Form 2 in Appendix).

\section{Procedures}

Clinician's opinion

Concerning the clinicians' form, five out of seven were completed and returned immediately via a face-to-face interview. Of the remaining two psychiatrists, one was unwilling to fill out the form citing that he spends too much time outside Lebanon and felt his input would be unrepresentative and the other was unreachable during the one month study period.

\section{Emergency episode practice}

Data were collected in the three main hospital wards throughout the study period. When patients are admitted either new or recurring - they must go through a centralised administrative system. Staff were informed regarding the study and recorded agitated episodes even when the researcher was not present, thus alerting him to the need for data acquisition. No episode was missed within the study period.

The researcher filled out the form by obtaining patients' case files and re-recording the treatments given during and after agitated episodes. If the patient continued having agitated episodes during the day, one form covered the period until the situation was tranquil. If the patient had one agitated episode and became tranquil but if it seemed as a new agitated episode occurred, this was considered a separate episode with one form per episode. After every form was completed, a unique ID was given for each individual to allow traceability but to guarantee anonymity.

\section{Results}

Clinicians

A total of seven psychiatrists were given the survey requesting their opinion of how aggression should be managed. Five completed the survey. All were selected on the basis of being employed in PHC. The five clinicians treated people with aggression daily (2), weekly (2) or monthly (1), worked across wards dealing with men or women and had a considerable depth of experience (see Table 2.

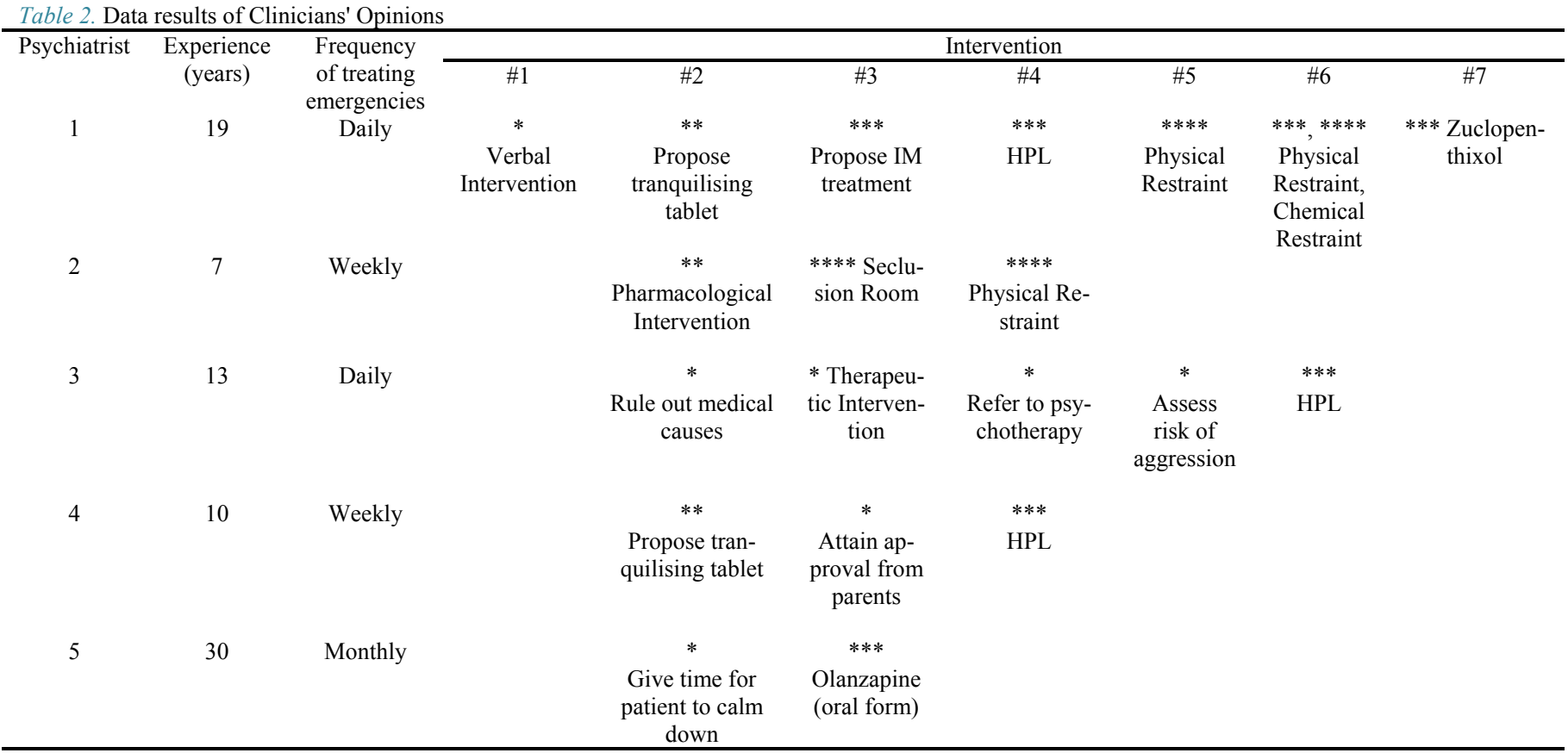




\begin{tabular}{|c|c|c|c|c|c|}
\hline Sex & Male & Female & & & Total \\
\hline & $25(64 \%)$ & $14(36 \%)$ & & & $39(100 \%)$ \\
\hline Age & $\begin{array}{c}\text { Mode } \\
31(n=6)\end{array}$ & $\begin{array}{l}\text { Mean } \\
33(\text { SD 8.9) }\end{array}$ & $\begin{array}{l}\text { Range } \\
18-58\end{array}$ & & \\
\hline Presentation & $\begin{array}{l}\text { Families } \\
26(67 \%)\end{array}$ & $\begin{array}{c}\text { Authorities } \\
3(8 \%)\end{array}$ & $\begin{array}{c}\text { By themselves } \\
4(10 \%)\end{array}$ & $\begin{array}{l}\text { Other } \\
6(15 \%)\end{array}$ & $\begin{array}{c}\text { Total } \\
39(100 \%)\end{array}$ \\
\hline Before admission & & & & & \\
\hline Restraints & $\begin{array}{c}\text { Yes } \\
7(18 \%)\end{array}$ & $\begin{array}{c}\text { No } \\
32(82 \%)\end{array}$ & & & $\begin{array}{c}\text { Total } \\
39(100 \%)\end{array}$ \\
\hline Medication & $\begin{array}{c}\text { Yes } \\
4(10 \%)\end{array}$ & $\begin{array}{c}\text { No } \\
35(90 \%)\end{array}$ & & & $\begin{array}{c}\text { Total } \\
39(100 \%)\end{array}$ \\
\hline
\end{tabular}

Data results of Clinicians' Opinions).

Clinicians' opinion of what interventions should take place

Psychiatrists suggested three broad categories of intervention - non-physical, medication and restrictive. All psychiatrists' first line of intervention were non-physical (non-pharmacological) preferring verbal intervention (talking down techniques). Thereafter, there was a drift to use oral medication followed by IM delivery choices. Clinicians tended to not be too specific about which oral medication to choose. The two IM treatments mentioned were haloperidol and zuclopenthixol acetate (Table 2).

\section{Clinical practice}

Patients' background and admission data

A total of 28 patients (39 episodes) were included in the one month survey of practice (1.26 people/day required rapid tranquilisation). All were adults of Lebanese nationality.

Most patients were male, in their early 30 s, and presented with their families. In a few instances restraints were used before admission ( $7 \%$ ) and people had already received some sort of medical intervention $(10 \%)$ such as being restraint or given medication by family, friends or self before being presented to the hospital (Table 3).

The male-only wards experienced a little higher frequency of agitated episodes but not crucially so (Table 4). Taken alone, bipolar disorder, was the most frequent single diagnosis $(n=12)$ but the collective schizophrenia-like illness (schizophrenia, schizoaffective disorder, delusional disorder, brief psychotic episode) totalled 13 of the 39 episodes.

\begin{tabular}{lcc} 
Table 4. Episode data & \\
\hline Ward & Male only & $18(46 \%)$ \\
\cline { 2 - 3 } & Male \& Female & $12(31 \%)$ \\
Female only & $9(23 \%)$ \\
Total & $39(100 \%)$ \\
& Sunday & $1(3 \%)$ \\
Monday & $12(30 \%)$ \\
Tuesday & $9(23 \%)$ \\
Frequency & Wednesday & $6(16 \%)$ \\
Diagnosis & Thursday & $7(18 \%)$ \\
& Friday & $2(5 \%)$ \\
& Saturday & $2(5 \%)$ \\
& Total & $39(100 \%)$ \\
& Range & $1-12 / \mathrm{day}$ \\
& Schizophrenia & $10(35 \%)$ \\
& Bipolar Disorder & $12(43 \%)$ \\
& Substance use & $3(10 \%)$ \\
& Schizoaffective Disorder & $1(4 \%)$ \\
& Brief Psychotic Disorder & $1(4 \%)$ \\
& Delusional Disorder & $1(4 \%)$ \\
& Total & $28(100 \%)$ \\
\hline
\end{tabular}

\section{Interventions used}

Table 5 includes the interventions used in the 39 emergency episodes.

\section{Verbal}

Every clinician had suggested that verbal interventions should be the first line. The survey form encouraged recording of both drug and non-drug approaches. However, in the entirety of the study, the verbal command was reported as being used only once as a first line of treatment.

\section{Medications}

All 39 agitated episodes received a first line treatment, $25(64 \%)$ received a second line intervention, $14(36 \%)$ a third, $8(21 \%)$ a fourth, $7(20 \%)$ a fifth and $1(3 \%)$ six interventions. All drug interventions were given IM - including clozapine which is available in this form in Lebanon - when patients were agitated and requiring rapid tranquilisation. There was no evidence that an oral option was given or offered - contrary to the clinician's opinion expressed in Table 2.

Diazepam IM was the most commonly used first and second-line drug treatment (total =16). It is known for causing residual pain at the site of injection and being erratic in its absorption (27-28). The second most used first-line intervention was a mix of haloperidol, promethazine, and chlorpromazine. This mixture, called "HPC" by the hospital is, according to hospital staff, the preferred 'SOS' [true emergency] treatment. It was used a total of seven times as first line treatment but, over the whole survey, it was the most commonly employed rapid tranquilisation $(n=18)$. The third most used was a haloperidol promethazine mix - four times as a first-line intervention.

The remaining drugs were benzhexol (an anticholinergic drug used to offset acute movements caused by antipsychotic drugs), or antipsychotics (chlorpromazine, clozapine, haloperidol, olanzapine, promethazine, zuclopenthixol) or benzodiazepines (diazepam, lorazepam) either used as a sole treatment or in combinations.

\section{Restrictive}

Although, from the reported preferences of clinicians, restraints were an available option, in reality, straitjackets were employed. Clinicians also had stated that restriction by use of restraints should be an option taken at least fourth after other measures. In reality, the strait jacket seems to have been used as first-line six times, and sec- 


\begin{tabular}{|c|c|c|c|c|c|c|c|}
\hline & & First & Second & Third & Fourth & Fifth & Sixth \\
\hline \multirow[t]{2}{*}{ Non-drug interventions } & Verbal Command & 1 & & & & & \\
\hline & Strait jacket & 6 & 2 & & & 1 & \\
\hline Drug interventions (all & Diazepam & 8 & 5 & 2 & 1 & & \\
\hline \multirow[t]{15}{*}{ IM) } & Haloperidol + Promethazine + Chlorpromazine & 7 & 5 & 4 & 1 & 1 & \\
\hline & Haloperidol + Promethazine +/- Benzhexol & 4 & 4 & & & & \\
\hline & Chlorpromazine + Lorazepam & 2 & & & & & \\
\hline & Lorazepam & 2 & 2 & 1 & & & \\
\hline & Zuclopenthixol + Promethazine & 2 & & & & 1 & \\
\hline & Chlorpromazine & 1 & 3 & 3 & 2 & 1 & \\
\hline & Chlorpromazine + Promethazine & 1 & & & & & \\
\hline & Diazepam + Lorazepam + Promethazine & 1 & & & & & \\
\hline & Haloperidol & 1 & & & & & \\
\hline & $\begin{array}{l}\text { Haloperidol }+ \text { Promethazine }+ \text { Chlorpromazine }+ \\
\text { Lorazepam }\end{array}$ & 1 & & & & & \\
\hline & Olanzapine & 1 & & & & & \\
\hline & Zuclopenthixol & 1 & & & & 1 & \\
\hline & Promethazine & & 4 & 1 & 4 & 2 & 1 \\
\hline & Clozapine & & 1 & & & & \\
\hline & Benzhexol & & & 3 & & & \\
\hline Total & & 39 & 25 & 14 & 8 & 7 & 1 \\
\hline
\end{tabular}

ond-line two (Table 5). In totality, the strait jacket ranked third most used intervention - both non-drug and drug - in the entire survey. Seclusion does not seem to have been used despite being one option suggested by the survey of clinician's opinion.

\section{Discussion}

\section{Overall}

This was, however, the first study of its kind in Lebanon to survey treatment options of both clinicians' opinions and practice in this difficult emergency situation. Out of necessity, it was small and short but its findings are not that different to other similar work. Few studies have undertaken parallel surveys of clinician's opinion alongside what happens to patients in their care and the survey of the doctors in Lebanon reported here was certainly limited in size. It did, however, suggest that desired practice is not really what happens on the front line - as was found by similar surveys (29-33).

There is no international consensus pertaining to the most effective treatment. The National Institute for Health and Care Excellence (NICE) guidelines suggest using lorazepam only in situations where there are not any nonpsychotic behavioural disturbance (34). Guidelines from the American Psychiatric Association (APA) (35) and from the Canadian Psychiatric Association (CPA) (36) both suggest using anti-psychotic drugs as first line treatment. The APA guidelines encourage haloperidol or atypical antipsychotics while the CPA guidelines suggest using the second-generation antipsychotic drugs. Unlike the CPA and NICE guidelines, the guidelines from the Royal Australian and New Zealand College of Psychiatrists (RANZP) (37) recommend zuclopenthixol even in drug naïve patients mainly to avoid repeated injections. The results of this survey share similarities in terms of using benzodiazepines and anti-psychotics alike. While the NICE recommends lorazepam which is available and used in the Lebanese practice, it is not the leading benzodiazepine option - which is diazepam. Lebanon shares more similarities with the APA, CPA, and RANZP that using antipsychotics as the emergency treatment intervention.
However, although Lebanon's haloperidol, promethazine and chlorpromazine combination is known to be used in other care settings (26), it is not seen in these major guidelines.

As regards that clinical front line, the age, sex and likely diagnosis of people presenting in this situation seems broadly similar to what is known from other surveys (3840). The exception is the absence of people with the diagnosis of personality disorder. The latter is not a diagnosis that is routinely recorded in Lebanon so figures reported in Table 4 may be under-representative of this diagnosis. It is also possible that people who present at the hospital are, in effect, pre-screened by the families and community services to really be only those with functional mental illnesses.

How the person arrived at the hospital gives a basic impression of the prevalent care-culture in Lebanon. Largely people were accompanied by one or more family member(s). Although a few did receive pre-admission medications (not listed) most presented without prescribed drugs. Seven people were placed in physical restraints before admission. When brought by police, handcuffs were used as a physical restraint, while a straitjacket was used if the patient was brought in by hospital staff.

The results for the survey of practice yielded four main intervention options. For the non-pharmacological interventions, the straitjacket was used eight times $(20 \%$; $95 \%$ CI 11-36\%). This survey did not have the details of its implementation, how long it was employed, the result of its use and if it caused adverse effects. Use of this approach has not been the study of much scientific enquiry and it is clearly a commonly used way of rendering the person safe in Lebanon.

Nearly half of first line treatments were either diazepam or a haloperidol plus promethazine mix (with a proportion of the latter having additional chlorpromazine). When non-pharmacological approaches are removed this proportion rises to $59 \%$. The most common first line sole drug treatment for rapid tranquilisation in this survey was intramuscular diazepam. This treatment is known to have erratic absorption and cause residual pain at the injection 
Table 6. Recommendations for first line treatment of aggression thought due to serious mental illness

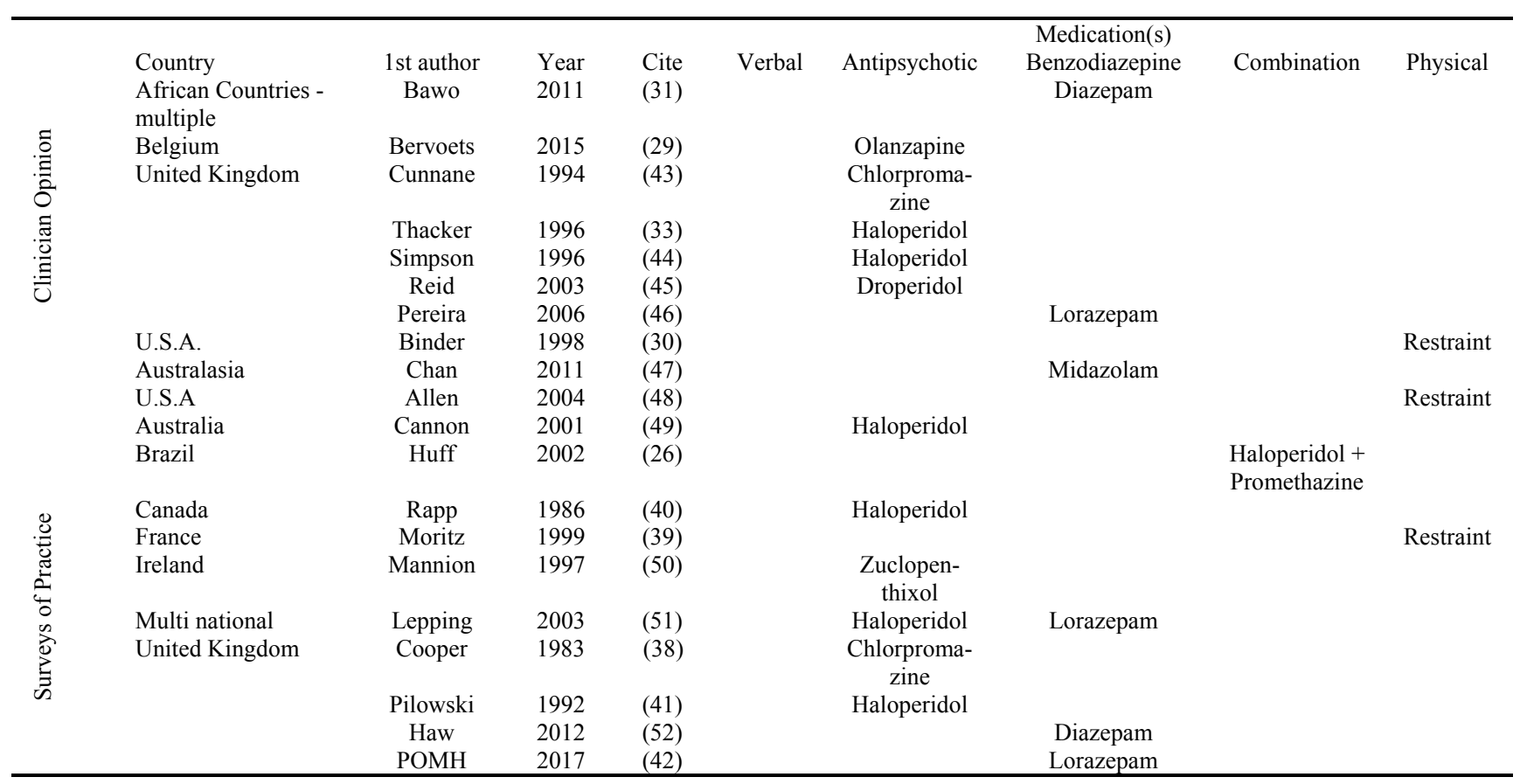

site (27-28). The first line use of diazepam was similar to the UK survey of the early 1990s (41) but this now seems to have been eclipsed in the UK by lorazepam (42). The latter is not heat stable and necessitates the use of fridges but these are available in Lebanon. It could be that the use of diazepam is an issue of availability and familiarity. The haloperidol plus promethazine mix was used 11 times first line but in seven instances additional chlorpromazine was added. This triple mix was the hospital's main 'SOS' treatment option for rapidly tranquilising agitated patients and here clinical practice does broadly concur with the opinion of the attending clinicians. This [likely potent] mix was also employed in Brazil (27).

Forty per cent of drug treatments were given only once or twice first line. Various combinations of chlorpromazine, diazepam, haloperidol, lorazepam, olanzapine, promethazine, and zuclopenthixol were used with no clear indication why these chosen as opposed to the diazepam or haloperidol/promethazine $+/$ - chlorpromazine mix. This proportion of 'various available variations' is similar to that seen in other surveys and is likely to be the result of a combination of clinical judgment and clinical freedom.

Although Lebanon favoured use of the haloperidolpromethazine-chlorpromazine combination more than has been seen in other countries (Table 6) but use of these drugs in this way has been seen elsewhere (27). Perhaps what is most striking are the similarities between Lebanon and the rest of the world. Clinicians here, as elsewhere $(30,39,43)$ recommend initial use of least restrictive options first, and then medications and finally restrictions on movements. Also, clinicians' choice in Lebanon, as elsewhere and out of necessity, takes into consideration resource, availability, and culture. In Lebanon, as for other places where both clinicians' recommendation or guidance has been considered alongside auditing or surveying of practice, such as the UK (42), there is a disparity between what clinicians want to happen and frontline clinical practice.

\section{Limitations}

This survey was small and short. Numbers, especially of the clinicians, were very small and it is important that two of the seven in the sample did not give information. However, we think the five to be representative of the whole group and had considerable experience in the field. We do not think that we failed to identify any instances of management of aggression during the sample period but it is possible that the high-quality recording of the use of straight jacket and pharmacological treatments (both in the drug cards) is systematically better than a description of attempts at verbal de-escalation. We may be underestimating the use of this technique in real practice.

\section{Conclusion}

This small, short, imperfect survey of clinician's opinion and practice, suggests that in Lebanon, as in other countries, what clinicians hope is undertaken in the emergency room is not necessarily what happens. This survey also suggested some consistency of clinical approach in Lebanon - partly out of necessity as there are limited approaches to take - but also partly out of clinician choice. Experienced clinicians in Lebanon, as for many other places, are repeatedly, routinely, using clearly effective treatments for managing people who are dangerous. The comparative quantified effects of these particular treatment approaches should be underpinned with good evidence from randomized trials.

\section{Acknowledgment}

No funding was provided for this study. Support was re- 
ceived from the Cochrane Schizophrenia Group with the supply of the data and library services as well as the University of Nottingham. We would like to thank Mere Arze Gemayel for her understanding and permission to carry out this survey within the hospital, Krystel El Adas for her record keeping assistance, clinicians, medical students, the sisters, nurses and all other staff involved that helped make this survey possible.

\section{Conflict of Interests}

The authors declare that they have no competing interests.

\section{References}

1. Tardiff K, Koenigsberg HW. Assaultive behavior among psychiatric outpatients. Am J Psychiatry. 1985;142(8):960-3.

2. Sachs GS, Printz DJ, Kahn DA, Carpenter D, Docherty JP. The expert consensus guideline series: medication treatment of bipolar disorder. Postgrad Med. 2000; Spec No:1-104.

3. Künzle B, Kolbe M, Grote G. Ensuring patient safety through effective leadership behaviour: a literature review. Safety Sci. 2010;48(1):1-17.

4. Fisher WA. Restraint and seclusion: a review of the literature. Am J Psychiatry. 1994;151(11):1584-91.

5. Atakan Z, Davies T. ABC of mental health. Mental health emergencies. BMJ. 1997;314(7096):1740.

6. Kaplan HI, Sadock BJ. Kaplan and Sadock's synopsis of psychiatry: Behavioral sciences/clinical psychiatry: Williams \& Wilkins Co; 1998.

7. Alexander J, Tharyan P, Adams C, John T, Mol C, Philip J. Rapid tranquillisation of violent or agitated patients in a psychiatric emergency setting. Br J Psychiatry. 2004;185(1):63-9.

8. Miles SH, Irvine P. Deaths caused by physical restraints. Gerontologist. 1992;32(6):762-6.

9. Douglas-Hall P, Whicher EV. 'As required' medication regimens for seriously mentally ill people in hospital. Cochrane Database Syst Rev. 2015;2015(12):CD003441.

10. Gillies D, Sampson S, Beck A, Rathbone J. Benzodiazepines for psychosis-induced aggression or agitation. Cochrane Database Syst Rev. 2013(4):CD003079.

11. Ahmed U, Jones H, Adams CE. Chlorpromazine for psychosis induced aggression or agitation. Cochrane Database Syst Rev. 2010(4):CD007445.

12. Berk M, Rathbone J, Mandriota-Carpenter SL. Clotiapine for acute psychotic illnesses. Cochrane Database Syst Rev. 2004(4):CD002304.

13. Muralidharan S, Fenton M. Containment strategies for people with serious mental illness. Cochrane Database Syst Rev. 2006(3):CD002084.

14. Du M, Wang X, Yin S, Shu W, Hao R, Zhao S, et al. De-escalation techniques for psychosis-induced aggression or agitation. Cochrane Database Syst Rev. 2017(4):CD009922.

15. Khokhar MA, Rathbone J. Droperidol for psychosis-induced aggression or agitation. Cochrane Database Syst Rev. 2016(12):CD002830.

16.Khushu A, Powney MJ. Haloperidol for long-term aggression in psychosis. Cochrane Database Syst Rev. 2016(11):CD009830.

17. Ostinelli EG, Brooke-Powney MJ, Li X, Adams CE. Haloperidol for psychosis-induced aggression or agitation (rapid tranquillisation). Cochrane Database Syst Rev. 2017(7): CD009377.

18. Huf G, Alexander J, Gandhi P, Allen MH. Haloperidol plus promethazine for psychosis-induced aggression. Cochrane Database Syst Rev. 2016(11): CD005146.

19. Belgamwar RB, Fenton M. Olanzapine IM or velotab for acutely disturbed/agitated people with suspected serious mental illnesses. Cochrane Database Syst Rev. 2005(2): CD003729.

20. Sailas EES, Fenton M. Seclusion and restraint for people with serious mental illnesses. Cochrane Database Syst Rev. 2000(1): CD001163.

21. Jayakody K, Gibson RC, Kumar A, Gunadasa S. Zuclopenthixol acetate for acute schizophrenia and similar serious mental illnesses. Cochrane Database Syst Rev. 2012(4): CD000525.

22. Ahmed U, Rehman F, Jones H, Adams CE. Risperidone for psychosis induced aggression or agitation. Cochrane Database Syst Rev. 2011(11): CD009412.

23. Vangala R, Ahmed U, Ahmed R. Loxapine inhaler for psychosisinduced aggression or agitation. Cochrane Database Syst Rev. 2012(11): CD010190.

24. Buckley P, Bartell J, Donenwirth K, Lee S, Torigoe F, Schulz SC. Violence and schizophrenia: clozapine as a specific antiaggressive agent. Bull Am Acad Psychiatry Law.1995;23(4):607-11.

25. Wilkie F, Fenton M. Quetiapine for psychosis-induced aggression or agitation. Cochrane Database Syst Rev. 2012(4): CD009801.

26. Huf G, da Silva Freire Coutinho E, Fagundes HM, Jr., Oliveira ES, Lopez JR, Gewandszajder M, et al. Current practices in managing acutely disturbed patients at three hospitals in Rio de Janeiro-Brazil: a prevalence study. BMC Psychiatry. 2002;2:4.

27. British Medical Association, Royal Pharmaceutical Society of Great Britain. British National Formulary: Vol. 49. Mehta, Dinesh, ed. Pharmaceutical Press; 2005.

28. Von Dardel O, Mebius C, Mossberg T, Svensson B. Fat emulsion as a vechicle for diazepam. a study of 9492 patients. Br J Anaesth. 1983;55(1):41-7.

29. Bervoets C, Roelant E, De Fruyt J, Demunter H, Dekeyser B, Vandenbussche L, et al. Prescribing preferences in rapid tranquillisation: a survey in Belgian psychiatrists and emergency physicians. BMC Res Notes. 2015;8(1):218.

30. Binder RL, McNiel DE. Emergency psychiatry: contemporary practices in managing acutely violent patients in 20 psychiatric emergency rooms. Psych Serv. 1999;50(12):1553-4.

31. James BO. Rapid tranquillization agents for severe behavioural disturbance: a survey of African psychiatrists' prescription patterns. Trop doc. 2011;41(1):49-50.

32. Pereira S, Paton C, Walkert LM, Shaw S, Gray R, Wildgust H. Treatment of acute behavioural disturbance: a UK national survey of rapid tranquillisation. J Psych Intens Care. 2005;1(2):84-8.

33. Thacker S. Junior doctors and emergency tranquillisation of elderly, confused patients: a survey. The Psychiatrist. 1996;20(4):212-4.

34. National Collaborating Centre for Nursing Supportive Care. Violence: The Short-Term Management of Disturbed/Violent Behaviour in In-Patient Psychiatric Settings and Emergency Departments. London: Royal College of Nursing (UK); 2005

35. Lehman AF, Lieberman JA, Dixon LB, McGlashan TH, Miller AL, Perkins DO, et al. Practice guideline for the treatment of patients with schizophrenia, second edition. Am J Psychiatry. 2004;161(2 Suppl):156.

36. Clinical practice guidelines. Treatment of schizophrenia. Can J Psychiatry. 2005;50(13 Suppl 1):7s-57s.

37. Royal Australian and New Zealand College of Psychiatrists clinical practice guidelines for the treatment of schizophrenia and related disorders. Aust N Z J Psychiatry. 2005;39(1-2):1-30

38. Cooper SJ, Browne FW, McClean KJ, King DJ. Aggressive behaviour in a psychiatric observation ward. Acta Psychiatr Scand. 1983;68(5):386-93.

39. Moritz F, Bauer F, Boyer A, Lemarchand P, Kerleau JM, Moirot E, et al. Patients in a state of agitation in a hospital emergency ward. [French]. Presse Med. 1999;28(30):1630-4.

40. Rapp MS. Chemical restraint. Can J Psychiatry. 1987;32(1):20-1.

41. Pilowsky LS, Ring H, Shine PJ, Battersby M, Lader M. Rapid tranquillisation. A survey of emergency prescribing in a general psychiatric hospital. Br J Psychiatry. 1992;160(6):831-5.

42. POMH-UK. Topic 16a. Rapid tranquillisation in the context of the pharmacological management of acutely-disturbed behaviour Prescribing Observatory for Mental Health-UK; 2017.

43. Cunnane J. Drug management of disturbed behaviour by psychiatrists. The Psychiatrist. 1994;18(3):138-9.

44. Simpson D, Anderson I. Rapid tranquillisation: A questionnaire survey of practice. Psychiatr Bull. 1996;20(3):149-52.

45. Reid G, Hughson M. Droperidol dropped; consultants not consulted. The Psychiatrist. 2003;27(8):301-4.

46. Pereira S, Dawson P, Sarsam M. The National Survey of PICU and Low Secure Services: 1. Patient characteristics. J Psych Intens Care. 2006;2(1):7-12.

47. Chan EW, Taylor DM, Knott JC, Kong D. Variation in the management of hypothetical cases of acute agitation in Australasian emergency departments. Emerg Med Australas. 2011;23(1):23-32

48. Allen $\mathrm{MH}$, Currier GW. Use of restraints and pharmacotherapy in academic psychiatric emergency services. Gen Hosp Psychiatry. 


\section{4;26(1):42-9}

49. Cannon ME, Sprivulis P, McCarthy J. Restraint practices in Australasian emergency departments. Aust N Z J Psychiatry. 2001;35(4):464-7.

50. Mannion L, Sloan D, Connolly L. Rapid tranquillisation: Are we getting it right? Psychiatr Bull. 1997;21(7):411-3.

51. Lepping P. The use of emergency psychiatric medication: a survey from 21 countries. J Clin Psychopharmacol. 2013;33(2):240-2.

52. Haw C, Stubbs J, Gibbon S. A survey of the use of emergency parenteral medication at a secure psychiatric hospital. J Psych Inten Care. 2013;9(2):77-84.

\section{Appendix}

Form 1. Clinicians' Form
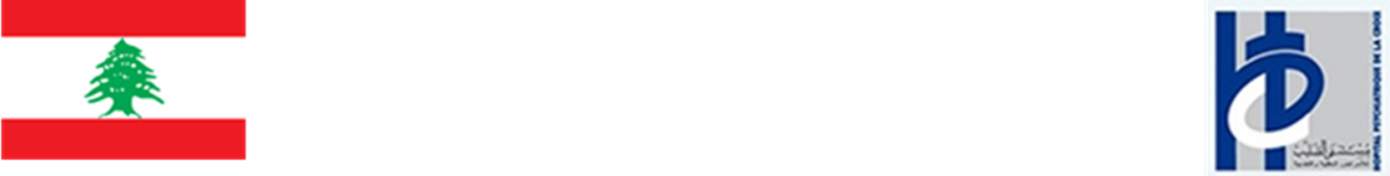

Name:

Role:

Ward:

Period of work in mental health:

QUESTION: How often would you have to manage a person who is acutely aggressive?

QUESTION: When someone is acutely aggressive - what do you think should be used to manage this?

*Note: Feel free to fill out the intervention steps based on the idea if previous intervention wasn't successful.

Intervention \#1:

Intervention \#2:

Intervention \#3:

Intervention \#4:

Intervention $\# 5$ :

Intervention \#6:

Intervention $\# 7$ :

Intervention \#8:

Intervention \#9:

Would you like to see the results of this survey? 
Form 2. Emergency Management Form

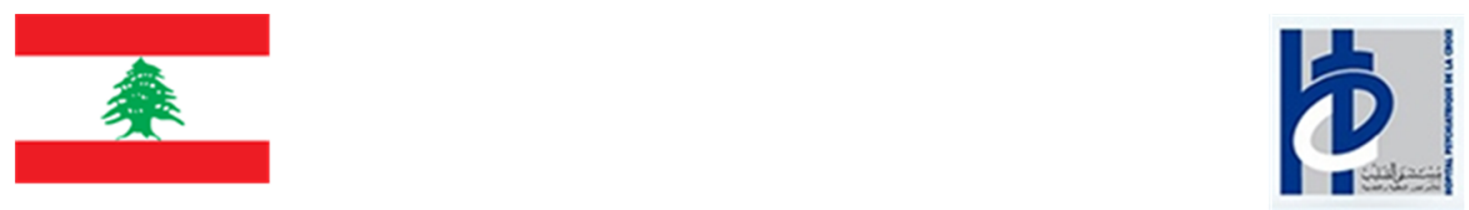

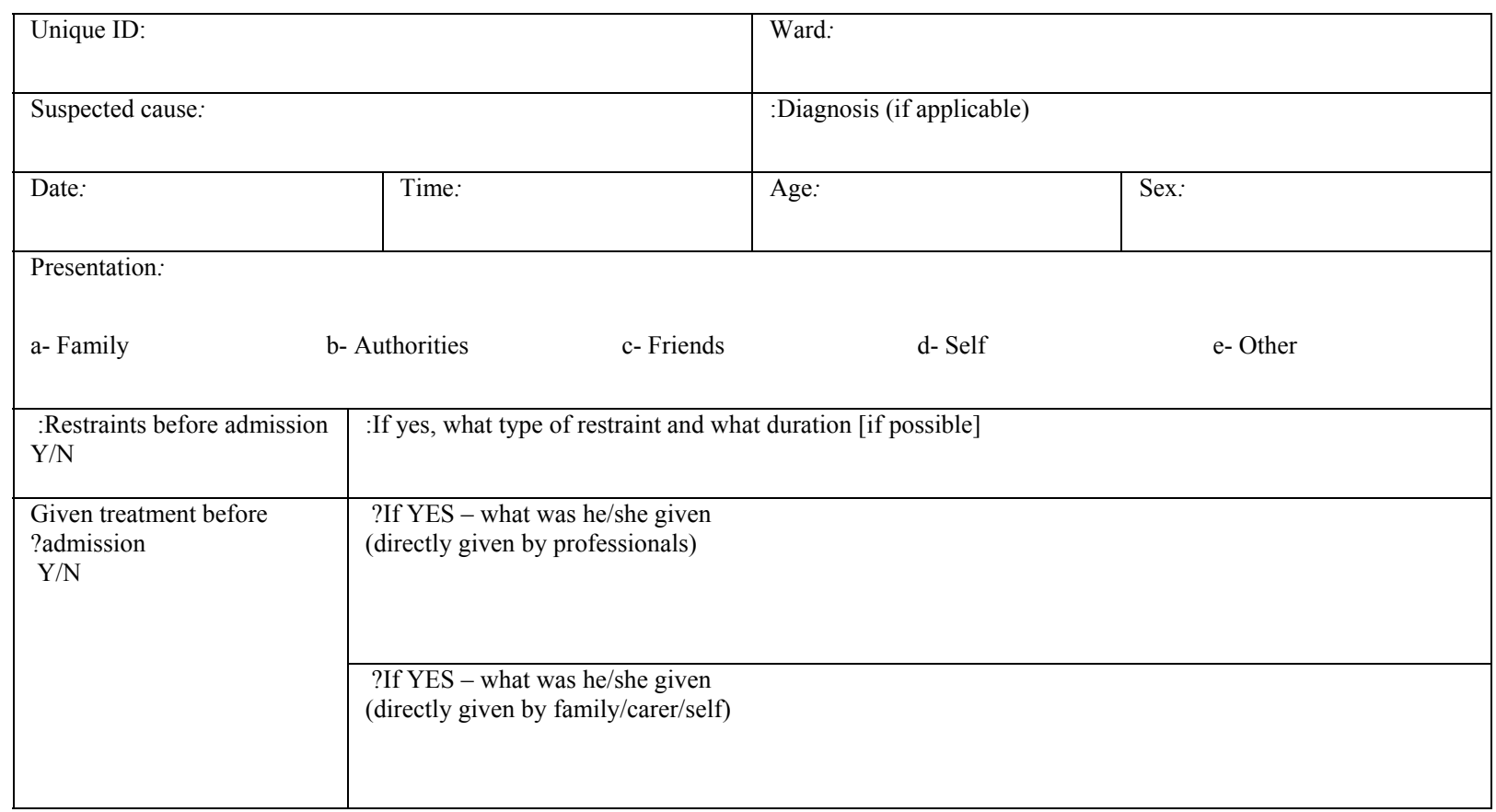

:Medication after admission for this episode [name, dose, route]

\begin{tabular}{|l|l|}
\hline \# Medication:1 & \\
\hline \# Medication: 2 & \\
\hline \# Medication:3 & \\
\hline \# Medication:4 & \\
\hline \# Medication:5 & \\
\hline \# Medication:6 & \\
\hline \# Medication:7 & PTO if necessary \\
\hline
\end{tabular}

